\title{
3D finite element analysis of the behaviour of cross passage between cast-iron tunnels
}

\author{
Zili Li ${ }^{\mathrm{a}^{*}}$, Kenichi Soga ${ }^{\mathrm{a}}$, Peter Wright ${ }^{\mathrm{b}}$ \\ ${ }^{a}$ Department of Engineering, University of Cambridge, Trumpington Street, \\ Cambridge CB2 1PZ, UK \\ ${ }^{\mathrm{b}} \mathrm{CH} 2 \mathrm{M}$ Hill UK Ltd, Elms House, 43 Brook Green, London W6 7EF, UK; formerly \\ Tube Lines Ltd, 15 Westferry Circus, Canary Wharf, London E14 4HD, UK
}

*Corresponding author. Address: Department of Engineering, University of Cambridge, Trumpington
Street, Cambridge CB2 1PZ, UK. Tel.:+44 (0)1223 748588; Fax.: +44 (0)1223 339713. E-mail
address:zl277@cam.ac.uk (Z. Li), ks207@cam.ac.uk(K. Soga), Peter.Wright@ch2m.com (P. Wright).

\section{ABSTRACT}

The behaviour of cast-iron cross passages in London Underground was investigated using 3D finite element models. Unlike the behaviour of a full tunnel ring, the structural integrity of a tunnel cross passage opening relies on the support from adjacent linings. In clayey soils, the opening may deform further as the soil stiffness changes from undrained to drained conditions. The degradation of circumferential bolts and trackbed may also lead to further tunnel movement. A parametric study was conducted to examine the influence of soil stiffness and structural components (e.g. bolts and lintel) on the structural integrity of a tunnel opening. Results show that a lintel effectively transfers the load above the opening to the adjacent linings, and its distortion affects tunnel deformation significantly. If a lintel is not present, both bolts and friction between tunnel segments provide shear resistance to the lining deformation at the tunnel opening against soil loading. The results are compared to the field observations made at a critical cross passage in one of the London Underground tunnels. The findings contributed to identifying the critical deformation 
mechanisms of cast-iron tunnel cross passages, which can be useful during inspection of such structures.

\section{KEYWORDS}

Cast iron lining, Cross passage tunnel, Bolt-spring model, Lintel, Bolts

\section{INTRODUCTION}

The condition of aging underground tunnels presents a significant engineering challenge in many cities (Inokuma and Inano 1996; Mair 2008). The London Underground has a history of more than 150 years and is one of the busiest underground metro systems in the world (Laver 2010; Wolmar 2004). Recent assessment conducted by Tube Lines (Wright 2010) shows that the engineering conditions of cross passages between adjacent cast-iron tunnels do not comply with modern standards.

A cross passage is a tunnel cut between two adjacent running tunnels with tunnel openings at both ends as a safe means of egress in case of emergency (PSCG PRC 2004). Completely lined with tunnel segments or in-situ cast concrete, the performance of the cross passage tunnel itself is generally in a good condition (Wright 2010). However, after removal of several segments when the tunnel was built, the structural integrity of the tunnel opening section in the main tunnel is impaired and has to rely on the adjacent structural members. In practice, visible deflection and other evidence of lining distress in some cross passage structures has been identified (Wright 2010). Nevertheless, the structural mechanism of tunnel openings is not well understood (Klappers et al. 2006; Zhang et al. 2007). Little literature is available in this field, even though cross passages between twin tunnels are commonly built in practice (Murray and Eskesen 1997). The limited publications mainly focus on lining design and construction from an industry perspective rather 
than investigating the issue in a scientific manner. That is, they usually introduce tunnel geometry and construction technique in details (Mayer et al. 2010; Li and Wang 2010), but seldom reveal the fundamental mechanism of 3D cross passage structural behaviour through field data interpretation or numerical / analytical analyses (e.g. FE modelling).

Unlike typical concrete segments, the structural features of bolted cast-iron linings are more complex as shown in Figure 1. A typical cast-iron tunnel segment consists of two radial flanges, two circumferential flanges and a panel section in the middle. To assemble a tunnel lining, the radial flanges of two segments are tightly bolted within one ring (Figure 1.b), whereas the circumferential flanges between two adjacent rings are often bolted loosely, which results in dislocation due to the installation imperfection or built tolerance (Figure 1.c). To facilitate bolt installation, there is a deeper groove between flanges in the circumferential joint than that in the radial joint. Waterproof materials like cement and wood packing are used to fill in the joint groove, but these materials are very flexible in comparison to cast iron. Previous research (Thomas 1977; Li et al. 2015) demonstrated that the structural performance of cast-iron lining is largely determined by the features of basic structural elements (e.g. tunnel segment and joints) mentioned above.

Unlike a fully continuous ring of a running tunnel, the deformation of a bolted tunnel cross passage involves longitudinal rotation and circumferential relative displacement between joints. Li et al. (2015) point out that the complexities of 3D bolted cast-iron tunnel lining behaviour cannot be considered using 2D plane strain analytical models such as by Duddeck et al. (1985) because of its unique shape that includes flanges, pans and joints. That is, a conventional beam-spring model (BSM) analysis, which models a joint as a spring and tunnel segments as shell or beam elements (e.g. Murakami et al. 1980), would fail to express the details of cast-iron joints (e.g. segment bending, joint distortion) (Klappers et al. 2006; Zhang et al. 2007; Wang et al. 2012). As an alternative, a new bolt-spring model was proposed by Li et 
al. (2014), which considers the bolts in joints as a set of springs and models tunnel segments and their contacts explicitly. By considering joint behaviour and tunnel geometry in precise manner, this new approach offered a more realistic solution against previous efforts (e.g. conventional beam-spring model) (Li et al. 2014).

In this study, a three dimensional finite element $(\mathrm{FE})$ analysis, which uses the new bolt-spring model, was performed to investigate the structural behaviour of tunnel openings. The influence of soil stiffness and structural components (e.g. bolts and lintel) on the structural integrity of tunnel opening was examined. The critical tunnel structural components, such as lintel, trackbed and bolts, were modelled explicitly, while the effect of tunnel construction was taken into account. Results indicate that a lintel across an opening effectively transfers the hoop thrust applied on the opened section to adjacent rings, and hence lintel distortion behaviour can be critical. Otherwise, if a lintel is not present, circumferential bolts as well as friction between segments provide resistance on lining deformation against soil loading. The results were compared to the field observations made at a critical cross passage in one of the London Underground tunnels. The modelled tunnel behaviour qualitatively shows agreement with the field observations, particularly at the critical sections like lintel buckling and lining movement, although an quantitative comparison was difficult due to lack of historical construction documents. The findings contributed to identifying the critical deformation mechanisms of cast-iron tunnel cross passages, which can be useful during inspection of such structures.

\section{BEHAVIOUR OF CAST IRON CROSS PASSAGE}

\subsection{Tunnel opening classifications and mechanism}

In a typical London underground tunnel, a bolted cast iron lining has thousands of segmental rings connected by circumferential bolts. For each ring, it generally consists of six segments or more jointed by radial bolts, with a small key 
segment at the crown. In London Underground, tunnel openings were built throughout the tube network and in all eras of deep tube construction (Tube Lines 2007). Each tunnel opening was built to meet the requirement in its specific condition based upon limited engineering design at that time (e.g. more than 70 years ago). Hence, the configuration of each tunnel opening is very unique and apparently different from one to the other as shown in Figure 2.

The constitution of an opening ranges from one ring to several rings and they are supported by a variety of structural mechanisms. Some openings are supported by adjacent bolted segments, which can be called bolt-supported openings. Other openings rely on the support both from the bolts as well as other structural components (such as a lintel), which can be called call lintel-supported openings. Tube Lines (2008) summarises that $21 \%$ tunnel openings are lintel-supported and $69 \%$ openings are bolt-supported. Hence, the structural performance of these two types of openings are of concern and thus examined in this study.

Figure 3 shows an illustration of a bolt-supported opening. According to the structural mechanism proposed by Tube Lines (2008), the segments around the opening are classified into five groups: 1) Group A comprises the segments directly above the opening; 2) Flanked by Group A, Group B carries the transferred load through bolt group 1 (i.e. Circle 1); 3) Away from the opening, Group C behaves as an abutment and hence further support the opening; 4) Group D withstands additional hoop loading through the segments above (i.e. Circle 2); and 5) Group E is invert segments covered by trackbed, which behaves as a stiff beam in the longitudinal direction constraining the lining deformation.

Likewise, the structural mechanism of a lintel-supported opening is similar to the bolt-supported one as shown in Figure 4. The critical sections in the openings are supposed to be 1) Bolt group 1 and lintel beam in shear (i.e. Circle 1); 2) Jamb support (D) to withstand additional hoop loading due to transferred forces through beam (i.e. Circle 2); 3) Bending Moment capacity of beam (i.e. Circle 3); 4) Adjacent 
segments to withstand additional hoop loading due to transferred forces through bolt group 1 (i.e. Circle 4); and 5) Adjacent segment (C) to withstand additional hoop loading due to transferred forces through bolt group 2 (i.e. Circle 5).

\subsection{Structural assessment by Tube Lines}

In London Underground, typical lining distress observed includes distortion and cracks in segments, bolt failures, and opening of segmental joints. Crack development in a tunnel segment is monitored using a typical tell-tale as shown in Figure 5a. In a similar manner, Tube Lines (Wright 2010; Tube Lines 2008) attached pieces of glass across two segments, which give an indicative assessment of joint distortion as shown in Figure 5b. If ongoing movement of a cross passage causes great concern, a real-time monitoring system with electro-levels and potentiometers would be deployed. For example, a five-ring lintel-support opening in the Northern Line was found to be critical as illustrated in Figure $5 \mathrm{c}$. At this site, which has been monitored for some 10 years using electrolevel and potentiometer sensors, some visible evidence of deterioration, such as joint opening and lintel bending, has been observed over the recent years. This tunnel opening is considered as a case study and its finite element analysis is given in the following sections.

A common approach to examine tunnel behaviour is the use of an elastic continuum method (ECM) proposed by Duddeck et al. (1985). In this model, the lining is assumed as a continuous ring surrounded by 'elastic' ground in plane-strain conditions. However, as stated above, this $2 \mathrm{D}$ plane strain assumption fails to express the details of segmental joints, which significantly affect the lining behaviour (see Blom et al. 1999; Klappers et al. 2006; Li et al. 2013). In particular, the 3D structural tunnel support of the opening in the tunnel longitudinal direction (e.g. bolts, lintel and friction between segments) cannot be taken into account, which is the subject of the study presented in this paper. 


\section{MODELLING OF CAST IRON CROSS PASSAGE AND COMPARISON WITH FIELD OBSERVATIONS}

\subsection{Finite element model}

In this study, a three dimensional finite element analysis of a tunnel opening was performed using ABAQUS 6.12 (ABAQUS Inc. 2012). Considering symmetry, a 1/2 FE model was used for the simulations of a five-ring opening in the Northern Line (see Figure 6). The model consists of two and a half ring opening in a lining of twelve and a half rings with a typical steel I-beam lintel (see Figure 6.b). The longitudinal dimension of the model was sufficient to minimise the boundary effect (Li 2014). The displacements of the longitudinal boundary at the far end were fixed, while the boundary condition at the near end simulated the symmetry.

The cast-iron segments, lintel and trackbed were modelled explicitly using eight-node brick solid elements (C3D8), while the bolts in the segmental joints were simulated using a new bolt-spring model proposed by Li et al. (2014) (see Figure 7). In this approach, a bolt is simplified as nine springs in the normal direction to carry normal force and bending moment (Figure 7c) and two springs in the two shear directions to carry tangential force (Figure $7 \mathrm{~d}$ ). The load-displacement curves of the bolt-spring model were derived from a separate study modelling bolts as 3D solid continuum and examining the rotational and shear behaviour of the integrated segment-bolt model (Li et al. 2014). In the rotational model (Figure 7c), the tensile spring stiffness is $1300 \mathrm{kN} / \mathrm{mm}$, until the bolt yields at $0.1 \mathrm{~mm}$ for radial bolt and $0.073 \mathrm{~mm}$ for circumferential bolt, respectively, whereas the compressive stiffness is negligible as the bolt becomes loose when the joint is compressed. In the shear model (Figure $7 \mathrm{~d})$, a small initial stiffness $(1.65 \mathrm{kN} / \mathrm{mm}$ for radial bolt and $0.33 \mathrm{kN}$ $/ \mathrm{mm}$ for circumferential bolt) at up to $6 \mathrm{~mm}$ is due to the bolt sliding inside the bolt hole clearance. Once the bolt gets engaged with the segment, the stiffness then rises 
rapidly until the bold yields at $65 \mathrm{kN}$ at $7 \mathrm{~mm}$ for radial bolt and for $8 \mathrm{~mm}$ circumferential bolt, respectively.

The contacts between the cast-iron segments and the steel lintel were modelled explicitly by the hard contact model available in ABAQUS 6.12 (ABAQUS Inc. 2012). This type of contact prevents the penetration of the two contact surfaces in compression and does not allow the transfer of tensile stress across the interface, whilst the friction coefficients are set to be 0.15 and 0.3 for segment-segment contact (iron and iron) and lintel-segment contact (steel and iron), respectively (Blau 2008). Such contact model allows the rotational and shear behaviour of segmental joints to be simulated realistically in conjunction with the bolt-spring models. The linear elastic-hardening plastic behaviour of the segments and the linear elastic-perfectly plastic behaviour of the steel lintel were taken into account, and their properties were calibrated against laboratory work by Thomas (1977) and standard reports (Gilbert 1977; Tube Lines 2005) as summarised in Table 1. The models and parameters described above are employed throughout this paper for both case study and parametric study, whereas their detailed discussion can be found in $\mathrm{Li}$ et al. (2014) and Li (2014).

The modelled cross passage with a tunnel diameter $D=3.8 \mathrm{~m}$ and a spacing $d^{\prime}=6 \mathrm{~m}$ is located at a depth of $19 \mathrm{~m}$ as illustrated in Figure $8 \mathrm{a}$. The vertical soil profile is as follows: (a) Made Ground and Alluvium, MG (0-3 m), (b) London Clay, LC (3-20.9 m), and (c) Lambeth Group Clay, LG (i.e. Woolwich and Reading Bed Clay, WRBC) (20.9-34.9 m). In order to focus on the complexity of the 3D structural behaviour of cast iron tunnels, the soil strata was not explicitly modelled as 3D solid elements but simplified as soil loading and soil springs support (see Figure 8b). As the external pressure applied to the tunnel, the soil loading with typical 'total stress' earth pressure coefficient $K=0.7$ (Tube Lines 2007) was applied. Unlike the in-situ effective earth pressure coefficient $\mathrm{K}_{0}$ for London Clay, the adopted coefficient $\mathrm{K}$ 
takes account of tunnelling-induced soil stress redistribution and long-term drainage effect on tunnel structural assessment (Tube Lines 2007). On the other hand, the interaction between soil and tunnel lining was considered through a set of elastic reaction springs. The soil spring stiffness values are radial springs $K_{r}=60 \mathrm{MPa} / \mathrm{m}$ and tangential springs $K_{t}=30 \mathrm{MPa} / \mathrm{m}$ converted from equivalent soil strata $E=110$ MPa, using the following equations (Duddeck et al. 1985; USACE 1997; Tiberti, et al. 2008):

$$
\begin{gathered}
K_{r}=E_{s} / R \quad(1) \quad K_{t}=K_{r} / 2 \\
E_{s}=E(1-v) /(1+v)(1-2 v)
\end{gathered}
$$

where $K_{r}$ is the radial soil spring stiffness, $K_{t}$ is the tangential soil spring stiffness, $R$ is the outer radius of tunnel, $E_{s}$ is the confined compression modulus of soil, $E$ is the Young's modulus of soil, $v$ is the Poisson's ratio of soil.

The parameters of the soil springs can generally model the change of ground response during consolidation from the undrained conditions immediately after construction to steady state seepage conditions (Tube Lines 2007; Wright 2013).

Furthermore Li et al. (2015) demonstrated the importance of the effect of tunnel construction on lining behaviour. In practice, at the segment assembly stage inside the shield, the self-weight of the lining distorts the tunnel ring, while the magnitude of distortion is represented by tunnel ovalisation $\delta$ defined as follows:

$$
\delta=\Delta D_{\max } / D_{0}
$$

where $\Delta D_{\max }$ is the maximum displacement inside the tunnel along the tunnel circumference, and $D_{0}$ is the original tunnel diameter.

The magnitude of tunnel ovalisation depends on the soil-tunnel contact area along the invert segments. Considering that, a set of soil spring was distributed along the invert segments in the FE model to represent the soil-tunnel boundary condition as illustrated in Figure 9a. It was found that the ovalisation induced by self-weight 
can be as much as $0.44 \%$ with a typical soil-tunnel contact area of $18.5 \%$ ( $\mathrm{Li}$ et al. 2015). A soil load was then applied to the tunnel ring, which was already distorted by self-weight, by placing soil springs around the whole circumference of the lining (see Figure $9 b)$. Subjected to soil loading, the tunnel further squatted to $0.55 \%$. After this, the cross passage construction was modelled by deactivating the tunnel segment at the tunnel axis level and then the lintel was added (see Figure 9c). This study utilises the finding of this earlier work by setting the initial conditions before tunnel opening for cross passage construction.

The actual soil-tunnel interaction can be more complex and this can be examined by modelling both soil and tunnel lining as continuum, which at present requires large computational power to solve. For a given computational power in this study, it was only possible to examine the structural details of cast-iron bolted openings by modelling the soil as springs.

\subsection{Results at Critical Sections}

In this study, the critical sections identified at a cross passage (e.g. bolt dislocation, lintel bending) in the Northern Line were considered. Since the exact conditions of the old cross passage section before and after its construction were not documented, the proposed FE model can only simulate the general tunnel behaviour qualitatively similar to the observations (see below), whereas an actual quantitative comparison between the model and field data was difficult to achieve. However, the results contributed to building up a better understanding of the structural mechanism of tunnel openings and to find critical components of the structure (see the next section). Such information will be useful when conducting further conditional assessment of cross passages.

Figure 10 shows the observed dislocation of the segments above the opening modelled in this study. The inclination of the glass (see Figure 10a\&b) indicates that 
the segments above the lintel moves inward to the tunnel with reference to the adjacent ring over many decades after construction. The observed segment movement is also noted in the FE model (see as circled in Figure 10c\&d). In this figure, the bluish colour represents negative horizontal displacement, whilst the reddish colour is for the positive displacement. In the circled section, the greenish colour of the segments above the lintel represents relatively smaller negative displacement than that of the adjacent segment at the full ring, which is indicated by bluish colour. That is, the segments above the lintel move inwards to the tunnel in comparison to the adjacent ring. At the full ring section, the rings squat by having positive horizontal displacement (red colour) at the right side of the tunnel and negative horizontal displacement on the opposite side. At the cross passage section, more horizontal movement builds up (light blue to dark blue colour) at the opening side due to its weaker structural integrity after the removal of tunnel segments. At the opposite of the opening side (the right side), the positive horizontal displacement reduces slightly. This shows that the tunnel at the cross passage section shifts towards the opening as shown schematically in the plan view given in Fig. 10e.

Figure 11.a shows the normal forces of the soil springs along the tunnel linings. For clearer illustration, only soil springs at the tunnel opening section and a full ring are displayed in Figure 11.b, whereas the springs at the rest of the lining are hidden. Large tension is indicated by red, while compression is indicated by blue. In this study, the spring can carry tension as long as the overall earth pressure (i.e. initial earth pressure equivalent force + spring generated force) is in compression. For a full ring, the tunnel "squats" subjected to earth pressure while the soil arching builds up (Li et al. 2015). In contrast, the incomplete rings are unable to sustain the overburden above the opening whereas the soil arching effectively takes over the load (highlighted in circled area of the figure) and hence significant tension forces develop in the springs. For example, the earth pressure near the opening (see the 
location indicated by a red arrow) is the sum of the initial earth pressure $314 \mathrm{kPa}$ and the spring equivalent tensile stress $-236 \mathrm{kPa}$, which equals to $78 \mathrm{kPa}$ in compression.

Figure $12 a \& b$ show that bending deformation is observed in the field along the bottom flange of the lintel at both ends (see the red circles). Furthermore, the web of the lintel develops a local buckling deformation as shown in Figure 13a\&b, while the deformation mode is illustrated in Figure 13c. The computed FE results in Figure $12 \mathrm{c}$ and $13 \mathrm{~d}$ show agreement with the field observation. The lintel is overloaded as it sustains significant soil pressure above the opening, which generates a tensile stress of $164 \mathrm{kPa}$ in the middle of the bottom flange (see the red circle in Figure 13e). Then the load is transferred to the adjacent tunnel segments under the two ends of the lintel, where considerable distortion builds up. Consequently, the segments under the lintel (i.e. the jamb) sustain the overburden load and turn out to be the most critical section in the lining as shown in Figure 14: the maximum compressive stress of $90 \mathrm{kPa}$ occurs in the tip of the circumferential flange (see the red circle in Figure 14a), while the maximum tensile stress of $43 \mathrm{kPa}$ in turn appears at the bottom of the flange as circled in Figure 14b.

\section{CRITICAL FACTORS ON THE BEHAVIOUR OF OPENING}

Subjected to soil loading, an opening for a tunnel cross passage is supported by structural components and the surrounding ground. Li et al. (2015) examined the influence of factors such as earth pressure coefficient $\mathrm{K}$ and tunnel construction on behaviour of linings in a running tunnel. As a step further, this study examined factors that affect the behaviour of an opening.

During the past decades, the rigidity of old cast-iron tunnel openings could have degraded due to steel lintel dislocation, the deterioration of trackbed, interface between segments, bolt loosening or even missing in the joints. However, many cast- 
iron segments are still in good conditions (Wright, 2010). Furthermore, the soil stiffness around the tunnel might have already gone through soil consolidation from undrained to drained conditions and in turn affected the lining performance (Peck 1969; Barratt et al. 1994; Wongsaroj 2005; Wongsaroj et al. 2007). To understand the deformation mechanism of tunnel opening with time, the effects of the timedependent changes in the selected supporting components (e.g. bolts, lintel and soil stiffness) can be evaluated by conducting a series of parametric studies. For brevity, the influence of lintel is examined specifically for the lintel-supported opening in the first section. Then, the bolt-supported opening without a lintel is considered to examine the influence of bolts, trackbed, friction between segments and soil stiffness. As a summary, the modelled tunnel opening behaviour will be examined against the structural mechanism described earlier by Tube Lines (2008) (refer to Figure $3 \& 4$ )

\subsection{Lintel}

A lintel is often placed across the opening in order to transfer the load applied to the opened section to the adjacent rings. Figure 15 shows the tunnel deformation of a lintel-supported opening. In comparison to the bolt-supported opening, the deformation of the segments is smaller and less localised as shown in Figure 15b. The opening ovalisation is $0.61 \%$, which is smaller than the bolt-supported case that gives an ovalisation of $0.64 \%$ (see later). The lintel effectively carries the thrust from the segments and strengthens the arching effect of the lining. Hence, the jamb in the lintel-supported opening sustains higher compression, which is induced by the thrust above, than the one in the bolt-supported opening as shown in Figure 15c.

In a lintel-supported opening, a critical factor for assessing the lintel behaviour is the gap between the lintel and the segment as shown in Figure 16. The gap can become as big as $10.7 \mathrm{~mm}$ at the external circumference of the lining and tapers towards the centre of the tunnel along the radial axis until the two flanges are in 
contact. Caulking materials like cement, wood or steel packing are filled inside the gap, but these materials may be flexible in comparison to cast iron.

In this study, the contact area between the flanges of the segment and lintel was assumed in four cases: 1) the whole area 2) half surface area 3) 1/4 surface area 4) $5 \%$ of the surface area as shown in Figure 16c. Figure 17 shows the deformation contours of the lintel with different contact conditions, whereas Figure 18 shows principal compressive stress contours. The lintel is observed from the tunnel side. Due to symmetry, it is a half model. Large deformation zone (red colour) is observed on the left side, which is the centreline of the lintel (i.e. symmetrical plane).

When the contact area is whole surface (Figure 17a) or half surface (Figure 17b), the hoop thrust transferred from the segments spreads throughout the flange of the lintel. Local bending deformation is observed at locations where the circumferential flanges of the segments meet because the stiffness of those flanges is higher than that of the panel section. Likewise, the web bends into the opening side (or the right side in the figures), since more compressive stress distributes at the left-hand side of the lintel transferred from the panel of the segments (see Figure 18a). Significant stress concentration appears at the end of the lintel as a shear band, which indicates the lintel transfers hoop thrust effectively as expected in the structural assessment by Tube Lines.

When the contact area is small (Figure $17 \mathrm{c}$ or d), the load from the segments is transferred through a small portion of lintel's flange at the right-hand side and thus very localised deformation occurs at the flanges. Likewise, the compressive stress concentrates at the right-hand side of the lintel as shown in Figure $18 \mathrm{c} \& \mathrm{~d}$. The web in turn bends towards the soil side (or the left side in the figures), which is opposite of the observations made in the previous cases.

The whole or half surface cases appear to match with many observations made in old cross passages of London Underground (see Fig. 13a\&b\&c), in which the lintel is bending away from the soil side. This indicates that caulking is 
transferring the load effectively into the lintel. If a lintel is bending towards the soil side, this may indicate that the lintel is not effectively supporting the load and may require further investigation. The discussion above points out that the contact between the lintel and the segments needs to be carefully examined when retrofitting an opening structure.

\subsection{Bolts}

In a bolt-supported opening, the load from soil pressure on the linings with an opening is transferred to the neighbouring full rings by bolts and friction between segments. The influence of bolts is considered in this section, while that of segmentsegment friction is considered in the next section.

Figure 19a show the tunnel displacement contours with and without radial flange bolts. The deformation remains almost unchanged since the compressive hoop thrust clamps the joints along the lining and therefore develops friction between the segments. Hence the crown segments of the opened section are not supported greatly by the radial bolts.

On the other hand, when the circumferential bolts and the trackbed are removed, the shoulder segments of the opened section loses support from the neighbouring full ring, inducing further ovalisation from $0.64 \%$ to $0.74 \%$. Fig. $19 \mathrm{~b}$ (i) show the displacement contours when the circumferential bolts are active. Relative displacements between rings are observed, suggesting that the circumferential bolts are transferring the loads from the opened section to the adjacent rings. As shown by the load-displacement curve of the circumferential bolts in Fig. $7 d$, the shear resistance increases after some displacement when the clearance between the bolt and the bolt hole is used up. When the circumferential bolts are removed, all the

shoulder segments of the opened section move toward the opening with large relative displacement between the opened rings and the neighbouring full ring as 
shown in Fig. 19b(ii). Correspondingly, the magnitude of the tunnel opening convergence (see D in Fig. 19a(i)) increases significantly from $13.3 \mathrm{~mm}$ to $24.0 \mathrm{~mm}$. Results show the importance of circumferential bolts compared to radial bolts for restricting the deformation of the opening.

\subsection{Friction}

Friction between segments also resists the sliding of tunnel openings against the adjacent rings. The deterioration of the segment-segment interface may weaken the capabilities of the friction and hence can result in further deformation. Figure 20(a)(ii) shows the tunnel deformation without the friction between segments (i.e. friction factor $=0$ ), which can be compared to Fig. 20 (a)(i) (i.e. friction factor $=0.4$ ). If the friction coefficient decreases from 0.4 to zero, the maximum tunnel deformation increases by $3.8 \%$ (i.e. from $21.0 \mathrm{~mm}$ to $21.8 \mathrm{~mm}$ ) as shown in Figure 20b, while the ovalisation increases from $0.64 \%$ to $0.65 \%$. Compared to the effect of the circumferential bolts and the trackbed, the contribution of friction between segments is limited in terms of constraining the deformation of the tunnel opening.

\subsection{Soil stiffness}

After tunnel construction in clayey soils, the tunnel usually "squats" during long-term consolidation until a fully drained steady-state condition is reached. This is due to change in effective stresses and pore pressures around the tunnel as well as change in the soil stiffness. To consider the general effect of consolidation, Tube Lines (2007) suggests the drained stiffness of soil spring for London clay (i.e. Drained $\mathrm{Kr}=60 \mathrm{MPa} / \mathrm{m}$ ) is half of that in undrained conditions (i.e. Undrained $\mathrm{Kr}=$ $120 \mathrm{MPa} / \mathrm{m}$ ). Further soil-fluid coupled FE analyses by Mair (2008) and Li (2014) indicate that the soil near the tunnels generally reaches a new steady state within 5 
years, after which the ground loading to the lining is then considered as drained conditions.

Figure 21 compares the tunnel deformation contours between the undrained and drained cases. The decrease in soil stiffness during consolidation allows more soil load to be applied on the lining. For a full ring, the tunnel first sustains an ovalisation of $0.44 \%$ induced by self-weight. When soil loading is applied, the ovalisation builds up to $0.50 \%$ in the undrained case and then consequently increases to $0.57 \%$ in the drained case. For the cross passage section, the tunnel opening process in undrained conditions squats from $0.44 \%$ to $0.54 \%$. This is then followed by an ovalisation of $0.64 \%$ in drained conditions. The maximum lining deformation occurs at the segments above the opening and it builds up from $18.1 \mathrm{~mm}$ immediately after construction (i.e. the undrained case) to $21.4 \mathrm{~mm}$ in the drained case (see Figure 21b).

Likewise, the compressive stress in the jamb under the opening considerably develops as shown in the red circle in Figure $21 \mathrm{c}$, and the maximum value builds up from $66 \mathrm{kPa}$ to $84 \mathrm{kPa}$ after soil drainage. This indicates that the time-dependant tunnel deformation and stress state subjected to soil consolidation can be significant. To focus on the complexity of the structural features of cast iron tunnel openings, only the soil change between drained and undrained conditions is considered in this study. Further work will be conducted to examine how earth pressure and soil stiffness changes during soil consolidation.

As a summary, the findings derived from the FE analysis are compared against the proposed structural mechanism in Figure 3\&4. For the bolt-supported opening (see Figure 3), the overburden at Group A is transferred through Bolt Group 1 to adjacent segments Group B, as expected. In addition to the proposed structural mechanism, the FE analysis showed that most of the overburden at Group A is sustained by the jamb (tunnel segment Group D) immediately next to the tunnel opening rather than Group C, whilst the effect of trackbed at Group E on tunnel 
deformation is very important. For the lintel-supported opening (Figure 4), the lintel across the tunnel opening transfers most of the overburden rather than the bolts at (Bolt Group 1 \& 2). The lintel distortion includes web buckling (Circle 4), shear band at the end (Circle 1) and bending deformation (Circle 3), as expected, whilst the distortion mode is determined by the contact area between the flanges of the segment and lintel as noted in the FE parametric study.

In this paper, the observed tunnel deformation was well matched with back analyses by a finite element model (i.e. Class-C1 prediction was presented when the performance had been already known). Although Class-C1 prediction was autopsy (Lambe 1973), the computed behaviour revealed the critical structural mechanism of tunnel openings, which can be useful during inspection and maintenance of such structures. Given reasonable computational power, the tunnel structure was modelled explicitly in this study, whereas the soil was simplified as springs which failed to consider complex soil features such as anisotropy, time-dependence in a precise manner. Ideally, long-term tunnel behaviour should be predicted before knowing the actual tunnel deformation (i.e. Class-A prediction). However, such prediction is very difficult as it requires comprehensive investigations of soil property at site, relative soil-lining permeability, any third party construction and etc, particularly limited by the lack of historical construction documents. On the other hand, Class-A prediction may involve complicated modelling of soil behaviour, but the tunnel structure usually has to be simplified as a continuous ring to save computational time. Such simplified tunnel model, where tunnel segments and bolts are not explicitly considered, may have difficulty in providing straightforward guidance for tunnel inspection and maintenance in the interest of London Underground.

\section{CONCLUSIONS}

The simulation of cross passage structures carried out in this study was first compared against field observations from a cross passage in the Northern Line as a 
case study and then used to explore the influence of supporting components on the structural performance of the opening. Results from the parametric study conducted in this study (see Table 2) underlines the importance of the effect of soil stiffness, bolts, trackbed and lintel on lining performance. The work builds up a state of the art understanding of the 3D structural mechanism of cast-iron cross passage structures since limited reference is available in this area (Klappers et al. 2006; Zhang et al. 2007). The conclusions derived from the FE modelling and the comparison with the field data are as follows:

1) The 3D structural mechanism of tunnel openings cannot be simply considered as a one ring case of tunnel linings. The soil load applied on the segments above the opening section is transferred through circumferential bolts and the lintel, and then consequently is sustained by the jambs under the opening. The computed tunnel behaviour is in line with field observations, which indicates that lintel, segments above openings and jambs are the most critical sections.

2) The structural integrity of tunnel opening relies on the support from adjacent rings. The lintel above the opening is a critical section for the stability of the cross passage. In particular, the contact between the lintel and segments is an important factor when assessing the structural behaviour of the lintel. If the flanges of the lintel and the segments are fully in contact (i.e. caulking is transferring the load effectively), the web of the lintel moves toward the tunnel side and the lintel would be able to carry the thrust above the opening effectively. When the lintel-segment contact area is small (i.e. caulking is not transferring the load), the web of the lintel moves forward the soil side and significant distortion would develop.

3) If a lintel is not present (i.e. a bolt-supported opening), circumferential bolts provide considerable support on the lining deformation. The thrust above the opening is first transferred through a small friction due to the circumferential bolt sliding inside the bolt hole clearance, and then by the significant bolt shear resistance after some displacement when the clearance is used up. On the contrary, the effect of segment- 
segment friction is not significant, while the removal of radial bolts affects little on the lining deformation.

4) Furthermore, in case of tunnelling in clayey ground, the effect of change in soil stiffness from undrained to drained conditions is found to be important. Further study will focus on this issue and examine how earth pressure changes during longterm soil consolidation.

\section{ACKNOWLEDGEMENT}

This work was supported by National Basic Research Program of China (973 Program: 2011CB013800), National Natural Science Foundation of China (No. 51508403) and the

Cambridge Trust scholarship. The authors would like to thank London Underground Limited for providing invaluable the photos and support.

\section{LIST OF FIGURE CAPTIONS}

Figure 1 Basic structural elements of cast-iron lining: (a) Tunnel segment (b) Radial joint (c) Circumferential joint (d) Bolt

Figure 2 Photos of tunnel openings: (a) One-ring opening (b) Two-ring opening with concrete arch (c) Three-ring opening with concrete arch (d) Four-ring opening with a lintel and concrete arch (e) Five-ring opening with a lintel (provided by London Underground Limited)

Figure 3 Illustration of a bolt-supported opening: (a) Illustration of the opening (side view) (b) 3D schemes (c) Drawings of a full cast-iron ring (front view) (d) Drawings of an incomplete ring at the opening (front view)

Figure 4 Illustration of a lintel-supported opening: (a) Illustration of the opening (side view) (b) 3D schemes (c) A adjacent ring near cross passage (front view) (d) An incomplete ring at the opening (front view)

Figure 5 Illustration of a cast-iron cross passage in the Northern Line: (a) A tell-tale across a crack (b) An indicative glass across a segmental joint (c) Illustration of a cross passage

Figure 6 Numerical model of the tunnel opening in the Northern Line: (a) Tunnel opening (b) Steel lintel 
Figure 7 Structural model of a cast-iron joint: (a) Bolt in a joint (b) Illustration of nine springs model at $X-X$ cross section (c) Spring model in rotational load d) Spring model in shear load (Li et al., 2014)

Figure 8 Modified bedded ring model: (a) The stratum conditions $\quad$ (b) Bedded ring model

Figure 9 Illustration of soil springs distribution along the tunnel lining: (a) Segment assembly stage (b) Soil loading stage (c) Cross passage stage

Figure 10 The inward movement of the opening: (a) the left end of the opening (b) the right end of the opening (c) the overview of the inward movement in the FE model (d) the local inward movement (the distortion is magnified to 10 times) (the tunnel movement is indicated by the red circle) (e) Illustration of the tunnel distortion (plan view)

Figure 11 Normal soil spring along the tunnel lining (the soil springs with tension forces is indicated by the black circle): (a) the whole soil springs along the lining (b) the soil springs at the tunnel opening and a full ring for clearer illustration

Figure 12 Bending deformation of the lintel above the opening: (a) The left end of the lintel (b) The right end of the lintel (provided by London Underground Limited) (c) The numerical model (the distortion is magnified to 5 times) (the lintel bending deformation is indicated by the red circle)

Figure 13 Buckling deformation of the lintel: (a) The front view of the lintel (b) The side view of the lintel (the web buckling is indicated by the red circle) (provided by London Underground Limited) (c) Illustration of the lintel distortion (d) The FE model (the distortion is magnified to 5 times) (e) Tensile stress in the lintel (the local tensile stress is indicated by the red circle)

Figure 14 Stress contours of the tunnel structure (The stress concentration is indicated by the red circle)

Figure 15 The deformation contour of the lintel-supported opening (the stress concentration in the jamb is indicated by the red circle)

Figure 16 Lintel-segment contact conditions

Figure 17 Deformation contours of the lintel at contact area between the lintel and the segments (the distortion is magnified to 5 times)

Figure 18 Compressive stress contours of the lintel at contact area between the lintel and the segments (the distortion is magnified to 5 times)

Figure 19 Deformation contour of the tunnel opening considering the effect of the bolts and the trackbed

Figure 20 Deformation contour under different friction factors

Figure 21 Structural behaviour of the tunnel opening under different soil stiffness

Formatted: No widow/orphan control Don't adjust space between Latin and Asian text, Don't adjust space between Asian text and numbers

Formatted: Justified, No widow/orphan control, Don't adjust space between Latin and Asian text, Don't adjust space between Asian text and numbers 


\section{REFERENCES}

ABAQUS Inc., 2012. ABAQUS User's Manual, Version 6.12. SIMULIA. www.simulia.com

Barratt, D.A., O'Reilly, M.P., and Temporal, J., 1994. Long term measurement of loads on tunnel linings in overconsolidated clay. Tunnelling'94, London, pp. 469-481.

Blau, P. J. 2008. Friction science and technology: from concepts to applications (section edition). CRC Press. Boca Raton.

Blom, C.B.M., Van, E.J., and Jovanovic., P.S. 1999. Three-dimensional structural analyses of the shield-driven "Green Heart" tunnel of the high-speed line south. Tunnelling Underground Space Technology 14 (2), pp.217-224.

Duddeck, H., and Erdmann J. 1985. On Structural Design Models for Tunnels in Soft Soil. Underground Space, Vol.9, pp.246-259.

Gilbert, G.N.J. 1977. Engineering data on grey cast irons - SI units. BCIRA Alvechurch, Birmingham.

Inokuma, A., and Inano, S. 1996. Road tunnels in Japan Deterioration and Countermeasures. Tunnelling and Underground Space Technology, Vol.11, pp. 305-309.

Klappers, C., Grubl, F., and Ostermeier, B. 2006. Structural analyses of segmental lining- coupled beam and spring analyses versus 3D-FEM calculations with shell elements. Tunnelling and Underground Space Technology, Vol.21, pp.254-255.

Lambe, T. W. 1973. Predictions in soil engineering. Geotechnique, Vol. 23, pp. 151202. 
Laver, R. 2010. Long-term Behaviour of twin tunnels in London Clay. Ph.D. thesis, University of Cambridge.

Li D., and Wang, H. 2010. Investigation into artificial ground freezing technique for a cross passage in metro. GeoShanghai 2010 Geotechnical Special Publication, pp. 294-299.

Li Z., Soga, K., Bian X., and Wright, P. 2013. Ovalisation of cast-iron bolted tunnels and their modelling. Proceedings of EURO: TUN 2013 Computational Methods in Tunneling and Subsurface Engineering, 2013, pp. 871-878.

Li Z. 2014. Long-term behaviour of cast-iron tunnel cross passage in London Clay. Ph.D. thesis, University of Cambridge.

Li Z., Soga, K., Wang, F., Wright, P., and Tsuno, K. 2014. Behaviour of cast-iron tunnel segmental joint from the 3D FE analyses and development of a new bolt-spring model, Tunnelling and Underground Space Technology, Vol. 41, pp. 176-192

Li Z., Soga, K., and Wright, P. 2015. Behaviour of cast-iron bolted tunnels and their modelling, Tunnelling and Underground Space Technology, 50, 250-269.

Mair, R. J. 2008. Tunnelling and geotechnics: new horizons. Geotechnique, Vol. 58, pp. $695-736$

Murray, M.J., and Eskesen, S.D. 1997. Design and construction of cross passages at the Storebalt eastern railway tunnel. Tunnelling 97 Conference, no. 1056

Mayer, P.M., Frodl, S., Friedemann, W., and Jouaux, R. 2010. Innovative solutions for driving cross passages in bored tunnels with segmental lining. Geomechanics and Tunnelling, Vol.3, pp.295-307.

Murakami, H., and Koizumi, A. 1980. On the behaviour of the tranverse joints of a segment. the 35th Annual Conference of the JSCE, pp.73-86. (in Japanese) 
Peck, R.B. 1969. Deep excavations and tunnelling in soft ground. Proceeding of the seventh international conference on soil mechanics and foundation engineering, Hamburg, State of the Art Volume, pp. 225-290.

The Professional Standards Compilation Group of People's Republic of China (PSCG PRC), 2004. JTG D70 - 2004 Code for design of road tunnel. Beijing. (in Chinese)

Thomas, H. 1977. Measuring the structural performance of cast Iron tunnel linings in the laboratory. Geotechnics Division, Building Research Station, Building Research Establishment, Department of the Environment. pp.29-36.

Tube Lines. 2005. Deep tube tunnel knowledge \& inspection programme annual work plan 2: Cast iron coring report. TLL-L001-N416-DTAAWP2-TUN-RPT-00019. London.

Tube Lines. 2007. Deep tube tunnel knowledge \& inspection programme annual work plan 2: Soil parameters report. TLL-L001-N416-DTAAWP2-TUN-RPT-00001. London.

Tube Lines. 2008. Deep tube tunnel knowledge \& inspection programme annual work plan 2: Cast iron Openings report. TLL-L001-N416-DTAAWP2-TUN-RPT00003. London

Wang, F., Huang, H., Soga, K., Li, Z., Zhang, D., and Tsuno, K. 2012. Deformation analysis of a tunnel with concrete segmental lining subjected to ground surface loading using novel joint model. Proceedings of the World Tunnel Congress 2012, pp. 364-366.

Wolmar, C. 2004. The Subterranean railway: How the London Underground was built and how it changed the city for ever. Atlantic. 
Wongsaroj, J. 2005. Three-dimensional finite element analysis of short and long-term ground response to open-face tunnelling in stiff clay. $\mathrm{PhD}$ thesis, University of Cambridge.

Wongsaroj, J., Soga, K., and Mair, R. J. 2007. Modelling of long term ground response to tunnelling under St James' Park London. Geotechnique, Vol 57, pp. $75-90$.

Wright, P. 2010. Assessment of London Underground tube tunnels - investigation, monitoring and analysis. Smart Structures and Systems, Vol.6, pp.239-262.

Wright, P. 2013. Validation of soil parameters for deep tube tunnel assessment. ICE Journal of Geotechnical Engineering, Vol.166, pp. 18 -30.

Zhang, Z., Xu, J., and Wan, X. 2007. Study of tunnel construction mechanics at intersection of horizontal adit and major tunnel in highway. Rock and Soil Mechanics, Vol.28, pp.247-254. (in Chinese). 